\title{
Investigation of the Antioxidative Potential of Various Solvent Fractions From Fruiting Bodies of Schizophyllum commune (Fr.) Mushrooms and Characterization of Phytoconstituents
}

\author{
Vijayakumar Mayakrishnan ${ }^{1}$, Noorlidah Abdullah ${ }^{1}$, Mohamad Hamdi Zainal Abidin ${ }^{1}$, Noor Hasni Mohd Fadzil ${ }^{1}$, \\ Norjuliza Mohd Khir Johari ${ }^{1}$, Norhaniza Aminudin ${ }^{1} \&$ Nurhayati Zainal Abidin ${ }^{1}$ \\ ${ }^{1}$ Mushroom Research Centre, Institute of Biological Sciences, Faculty of Science, University of Malaya, Kuala \\ Lumpur, Malaysia
}

Correspondence: Vijayakumar Mayakrishnan, Mushroom Research Centre, Institute of Biological Sciences, Faculty of Science, University of Malaya, Kuala Lumpur 50603, Malaysia. Tel: 603-7967-4370. E-mail: drvijay@um.edu.my

Received: March 27, 2013 Accepted: April 26, 2013 Online Published: May 15, 2013

doi:10.5539/jas.v5n6p58 URL: http://dx.doi.org/10.5539/jas.v5n6p58

\begin{abstract}
The aim of the present study was to investigate the antioxidative potential of components extracted from the indigenous medicinal mushroom, Schizophyllum commune, using solvents of different polarities. The effectiveness of antioxidants in each solvent fraction was evaluated by quantitating the total phenolic content, 1,1-diphenyl-2-picrylhydrazyl (DPPH) radical scavenging activity, cupric ion reducing antioxidant capacity (CUPRAC), peroxidation inhibition in the egg yolk system, metal chelating potential, and $\beta$-carotene bleaching activity. Our findings revealved that the ethyl acetate fraction of $S$. commune had a phenolic content of $82.42 \pm 7.23$ and exhibited good activities for DPPH radical scavenging (70.52 $\pm 2.17 \%)$, CUPRAC $(0.38 \pm 0.03)$, peroxidation inhibition $(73.38 \pm 1.39 \%)$, metal chelating $(81.29 \pm 4.19 \%)$, and $\beta$-carotene bleaching $(63.25 \pm 2.5 \%)$ at concentration of 0.1 to $1.0 \mathrm{mg} / \mathrm{mL}$. In addition, gas chromatography-mass spectrometry and liquid chromatography-tandem mass spectrometry were used to determine the volatile and non-volatile constituents of the potent antioxidative ethyl acetate fraction from cultivated $S$. commune fruiting bodies. This comprehensive analysis demonstrates that the ethyl acetate fraction of $S$. commune fruiting bodies is a viable source of natural antioxidants that can be utilized for functional foods and nutraceutical applications.
\end{abstract}

Keywords: volatile, ethyl acetate, oxidative stress, free radical, total phenolic content

\section{Introduction}

Numerous physiological processes in living organisms produce oxygen-centered free radicals and other reactive oxygen species (ROS) as by-products. The most common free radical species are superoxide radicals, peroxide radicals, reactive nitrogen radicals and nitric oxide (Halliwell, 1996). The uncontrolled production of free radicals and ROS can result in cell death and tissue injury (Cheung et al., 2005). Oxidative damages caused by free radicals contributes to a wide variety of pathological conditions, including atherosclerosis, respiratory disorders, neurodegenerative diseases, inflammatory diseases, cancer, hypertension and ageing (Anderson, 1999). Almost all organisms have evolved antioxidant defenses and repair systems to protect them against oxidative damage. For example, mammalian cells possess intracellular antioxidants, such as superoxide dismutase, catalase, and glutathione peroxidase, which protect against the formation of free radicals (Ferreira et al., 2006). However, these systems are insufficient to completely prevent oxidative damage. Thus, exogenous dietary antioxidants, which can scavenge free radicals and oxidants, have been suggested as beneficial protective agents for the human body. Therefore, the consumption of dietary antioxidants might prevent diseases.

Mushrooms are functional foods that can be a great source of nutrition and physiologically beneficial, non-toxic medicine (Wasser \& Weis, 1999). Mushrooms can contain a wide variety of free radical scavenging molecules, including polysaccharides, polyphenols, and dietary antioxidants (vitamin C, E, and carotenoids) that have been of particular interest in the fight against degenerative diseases. So far, phenolic compounds are considered to be one of the most important non-essential dietary components for inhibiting free radicals in the prevention of vascular diseases, some forms of cancer, and destructive oxidative stress (damaging DNA, protein and 
membranes) (Rabajoli et al., 1996). Some researchers have even indicated that phenolic substances, such as flavonoids and phenolic acids, are considerably more potent antioxidants than vitamin $\mathrm{C}$ and $\mathrm{E}$ (Cao et al., 1997).

Schizophyllum commune (Fr.) is an-edible mushroom that is widely distributed, growing on every continent except Antarctica (Yim et al., 2009). For this reason, this mushroom has been the object of numerous studies related to, sexuality, genetics, and morphogenesis. In addition, Oso (1981) reported that S. commune has significant medical properties. Infact, studies have indicated that schizophyllan, a polysaccharide isolated from $S$. commune, is a promising therapeutic agent, which displays antitumor, anticancer, and immunomodulating activities. Indeed, recent scientific reports identifying biologically active compounds within various mushrooms have validated their medicinal efficacy (Lindequist et al., 2008). In spite of the potential medical benefits related to $S$. commune, its phenolic content, antioxidative activity, and chemical composition have not been well estabilished. Therefore, in this study, we aimed to investigate the antioxidative activities and myco-chemical characterization of solvent fractions obtained from $S$. commune fruiting bodies.

\section{Method}

\subsection{Cultivation of S. Commune Fruiting Bodies}

S. commune was cultivated in plastic bags using sawdust as a substrate. The harvested mushroom fruiting bodies were rinsed first with tap water and then with de-ionized water. The mushrooms were dried $50-60^{\circ} \mathrm{C}$ and then ground into a fine powder using a blender. The antioxidative compounds present in the $S$. commune fruiting bodies were then extracted with various solvents.

\subsection{Preparation of Solvent Extract and Fractions}

The preparation of mushroom extract and solvent fractions was performed according to the method of Duan et al. (2006) with some modification. Schizophyllum commune powder $(500 \mathrm{~g})$ was extracted with $2.5 \mathrm{~L}$ of methanol: dichloromethane $(2: 1)$ in an air tight, clean flat bottomed container for 3 days at room temperature with occasional stirring and shaking. The extract was then filtered through Whatman No 1 filter paper. The extraction was repeated twice. The organic solution from each extraction was combined and evaporated under vacuum until dry, yielding crude extract, which was then dissolved in $90 \%$ aqueous methanol. The solution was partitioned with hexane $(3 \times 100 \mathrm{~mL})$, and the aqueous methanol was evaporated under reduced pressure to give a semisolid, which was then dissolved in $100 \mathrm{~mL}$ of distilled water and further partitioned successively with dichloromethane $(\mathrm{DCM} ; 3 \times 100 \mathrm{~mL}$ ) and ethyl acetate (EA; $3 \times 100 \mathrm{~mL})$, respectively (Figure 1).

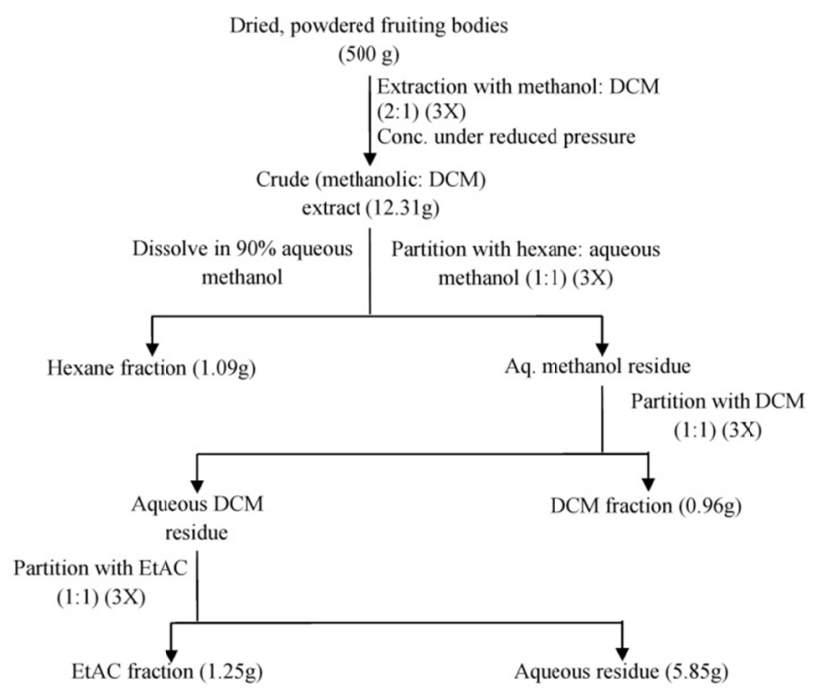

Figure 1. Extraction and fractionation of fruiting bodies of $S$. commune mushroom

\subsection{Sources of the Chemicals}

The chemicals used in the present study were of analytical reagent grade and were purchased from Sigma-Aldrich. 


\subsection{Investigation of Antioxidant Activity of S. commune Mushrooms}

The antioxidant potential of S. commune solvent fractions was investigated using the following standard assays and compared to quercetin, a natural antioxidant compound.

\subsubsection{Total Phenolic Content (TPC)}

TPC of S. commune solvent fractions were quantified using Folin-Ciocalteu reagent based on a modified version of the Slinkard and Singleton method (1977). Briefly, $250 \mu \mathrm{L}$ of $10 \%$ Folin-Ciocalteu reagent, was added to 250 $\mu \mathrm{L}$ of each solvent fraction and shaken. After 2 minutes, $500 \mu \mathrm{L}$ of $10 \%$ sodium carbonate solution was added. The mixture was incubated in the dark for $1 \mathrm{~h}$ before absorbance was read at $750 \mathrm{~nm}$. TPC was calculated on the basis of the calibration curve of gallic acid $(2-10 \mu \mathrm{g} / \mathrm{mL})$ and expressed as gallic acid equivalents (GAEs), in $\mathrm{mg} / \mathrm{g}$ of extract.

\subsubsection{Scavenging Effect on 1,1-diphenyl-2-picrylhydrazyl (DPPH) Radicals}

The DPPH radical scavenging assay was done following the method of Noorlidah et al. (2012). Aliquot $(0.1 \mathrm{~mL})$ of each solvent fraction with different concentration $(0.1$ and $100 \mathrm{mg} / \mathrm{mL})$ was mixed with $3.9 \mathrm{~mL}$ of $0.06 \mathrm{mM}$ DPPH dissolved in methanol. The solution was shaken vigrorously and the absorbance was measured at $515 \mathrm{~nm}$, using methanol as blank. The decrease in absorbance was monitored at $0 \mathrm{~min}, 1 \mathrm{~min}, 2 \mathrm{~min}$, and every $15 \mathrm{mins}$ until the reaction reached its plateau. The percentage of free radical scavenging activity, was calculated using the following equation:

$$
\text { Radical scavenging activity (\%) }=A_{0} A_{s} / A_{0} \times 100
$$

where $A_{0}$ is the absorbance of $0.06 \mathrm{mM}$ methanolic DPPH only, and $A_{s}$ is the absorbance of the reaction mixture. $\mathrm{IC}_{50}$ value (half maximal inhibitory concentration) of the most potent solvent extract was calculated from the graph of radical scavenging activity against extract concentration.

\subsubsection{Cupric Ion Reducing Antioxidant Capacity (CUPRAC)}

The CUPRAC assay was performed according to the method of Ozturk et al. (2007) with some modifications. The test mixture contained $1 \mathrm{~mL}$ of each of the following: $10 \mathrm{mM}$ of copper (II), $7.5 \mathrm{mM}$ neocuproine, and $1 \mathrm{M}$ ammonium acetate buffer ( $\mathrm{pH} 7.0)$. Briefly, $1 \mathrm{~mL}$ of solvent fraction $(0.1-100 \mathrm{mg} / \mathrm{mL}$ ) was added to each reaction tubes to achieve a final volume of $4 \mathrm{~mL}$. The tubes were then incubated for $30 \mathrm{~min}$ at room temperature before absorbance at $450 \mathrm{~nm}$ was recorded against a blank.

\subsubsection{Inhibition of Lipid Peroxidation of Buffered Egg Yolk}

Inhibition of lipid peroxidation was determined according to the method of Daker et al. (2008). Briefly, the reaction mixture contained $1 \mathrm{~mL}$ of fowl egg yolk emulsified with $0.1 \mathrm{M}$ phosphate buffer ( $\mathrm{pH}$ 7.4) to obtain a final concentration of $25 \mathrm{~g} / \mathrm{L}$ and $100 \mu \mathrm{L}$ of $1000 \mu \mathrm{M} \mathrm{FeSO}_{4}$. Concentration of $0.1-100 \mathrm{mg} / \mathrm{mL}$ of each solvent fraction was added, shaken and incubated at $37^{\circ} \mathrm{C}$ for $1 \mathrm{~h}$ before being treated with $0.5 \mathrm{~mL}$ of freshly prepared $15 \%$ trichloroacetic acid (TCA) and $1.0 \mathrm{~mL}$ of $1 \%$ thiobarbituric acid (TBA). The reaction tubes were further incubated in a boiling water bath for $10 \mathrm{~min}$. The tubes were then cooled to room temperature and, centrifuged at $3,500 \mathrm{~g}$ for $10 \mathrm{~min}$ to remove the precipitated protein. Finally, the formation of thiobarbituric acid reactive substances (TBARS) in $100 \mu \mathrm{L}$ of supernatant was determined by reading the absorbance at $532 \mathrm{~nm}$. Buffered egg with $\mathrm{Fe}^{2+}$ only was used as control in this assay. The percentage inhibition $\left(\mathrm{IC}_{50}\right)$ was calculated using the following equation:

$$
\text { Inhibition }(\%)=A_{0} A_{s} / A_{0} \times 100
$$

where $A_{0}$ is the absorbance of the control, and $A_{s}$ is the absorbance of the sample. $\mathrm{IC}_{50}$ value (half maximal inhibitory concentration) of the most potent solvent extract was calculated from the graph of inhibition of lipid peroxidation against extract concentration.

\subsubsection{Metal Chelating Activity}

The ability of the fraction to chelate iron (II) was estimated according to the method of Dastmalchi et al. (2008). An aliquot of each sample $(200 \mu \mathrm{L})$ was mixed with $100 \mu \mathrm{L}$ of $\mathrm{FeCl}_{2} \cdot 2 \mathrm{H}_{2} \mathrm{O}(2.0 \mathrm{mmol} / \mathrm{L})$ and $900 \mu \mathrm{L}$ of $\mathrm{MeOH}$. After $5 \mathrm{~min}$, the reaction was initiated by addition of $400 \mathrm{~mL}$ of ferrozine $(5.0 \mathrm{mmol} / \mathrm{L})$ and further incubated for $10 \mathrm{~min}$. Then absorbance was read at $562 \mathrm{~nm}$. The chelating activity (\%) was calculated using the following equation:

$$
\text { Chelating activity }(\%)=\left[A b s_{\text {control }}-\left(A b s_{\text {sample }} / A b s_{\text {control }} X 100 .\right.\right.
$$




\subsection{6 $\beta$-carotene Bleaching Assay}

$\beta$-carotene bleaching activity of the various mushroom solvent fractions $(0.1$ to $100 \mathrm{mg} / \mathrm{mL})$ was evaluated according to the method of Noorlidah et al. (2012) with some modifications. Briefly, $2 \mathrm{mg}$ of $\beta$-carotene was dissolved in $10 \mathrm{~mL}$ of chloroform. Then, linoleic acid $(40 \mu \mathrm{L})$ and Tween 80 emulsifier $(400 \mu \mathrm{L})$ were added to this mixture and subsequently chloroform was evaporated under vacuum prior to the addition of $100 \mathrm{~mL}$ of distilled water. Then, $4.8 \mathrm{~mL}$ of this mixture was mixed with various concentrations of each solvent fractions and the absorbance was measured at $470 \mathrm{~nm}$. The percentage inhibition was calculated using the following formula:

$$
\text { Inhibition }(\%)=A_{0} A_{s} / A_{0} \times 100
$$

where $A_{0}$ is the absorbance of the control, and $A_{s}$ is the absorbance of the sample.

\subsection{Mycochemical Characterization of S. commune}

2.5.1 Liquid Chromatography -Tandem Mass Spectrometry (LC-MS/MS) Analysis of the Ethyl Acetate Fraction of $S$. commune

The LC-MS/MS analyses were carried out using AB Sciex 3200 Q trap with Perkin Elmer UHPLC FX15. The chromatograph was coupled to an electrospray ionization (ESI) mass spectrometer through a turbo $\mathrm{V}$ spray source. The analytical condition employed a phenomenex aqua column $(50 \mathrm{~mm} \times 2.1 \mathrm{~mm}$, particle size $3 \mu \mathrm{m})$, mobile phase nitrogen, an, optimum flow rate of $0.4 \mathrm{~mL} / \mathrm{min}$, and an injection volume of $10 \mu \mathrm{L}$. The diode array detector recorded the spectra from 100 to $1200 \mathrm{~nm}$. The MS analyzer was operated in the ESI negative mode.

\subsubsection{Gas Chromatography-Mass Spectrometry (GC-MS) Analysis of the Ethyl Acetate Fraction of S. commune}

GC/MS analyses were performed on a gas chromatograph directly coupled to a mass spectrometer system. HP-5ms silica capillary column ( $30 \mathrm{~m}$ x $250 \mu \mathrm{m}, 0.25 \mu \mathrm{m}$ film) was used under the following conditions: oven temperature program from $70^{\circ} \mathrm{C}(2 \mathrm{~min})$ to $300^{\circ} \mathrm{C}(6 \mathrm{~min})$ with the final temperature maintained for $29 \mathrm{~min}$; injector temperature of $250^{\circ} \mathrm{C}$; He carrier gas, flow rate of $1 \mathrm{~mL} / \mathrm{min}$; injection volume of $1.5 \mu \mathrm{L}$; splitless injection technique; ionization energy of $70 \mathrm{eV}$, electronic ionization (EI) mode; ion source temperature of $200{ }^{\circ} \mathrm{C}$; scan mass range of $50-550 \mathrm{~m} / \mathrm{z}$; and interface line temperature of $300^{\circ} \mathrm{C}$. Peak identification was based on comparison with mass spectra from the National Institute of Standards and Technology (NIST 08 and NIST 08 s) library and published data.

\subsection{Statistical Analysis}

All experiments were performed in triplicate and data were recorded as means \pm standard deviations. Statistical analyses were carried out using one-way analysis of variance (ANOVA). Differences among means were analysed by least significant difference at $95 \%(\mathrm{P}<0.01)$.

\section{Results and Discussion}

\subsection{TPC}

As shown in Figure 2a, analysis of the distribution of phenolic compounds in $S$. commune solvent fractions revealed that the dichloromethane fraction contained the highest phenolic content $(86.51 \pm 6.70 \mathrm{mg} \mathrm{GAE} / \mathrm{g})$, followed by the ethyl acetate $(82.42 \pm 7.23 \mathrm{mg} \mathrm{GAE} / \mathrm{g})$, aqeous residue $(59.39 \pm 8.13 \mathrm{mg} \mathrm{GAE} / \mathrm{g}$ ), crude $(41.51 \pm 1.14 \mathrm{mg} \mathrm{GAE} / \mathrm{g})$, and hexane $(37.12 \pm 4.77 \mathrm{mg} \mathrm{GAE} / \mathrm{g})$ fractions. In regard to the relationship between TPC and the antioxidant activity, it has been reported by several researchers that phenolic compounds in mushrooms significantly contribute to their antioxidant properties. In this study, there was positive correlation between TPC and metal chelating ability $\left(r^{2}=0.765\right)$, which was highly significant $(p<0.001)$. In addition, there was significant correlation between TPC and antioxidant capacity $\left(\mathrm{r}^{2}=0.415, \mathrm{p}<0.001\right)$, as shown by the $\beta$-carotene bleaching assay. Indeed, antioxidant activity increased proportionally to the phenolic content, and a linear relationship between DPPH-radical scavenging activity and TPC was established $\left(r^{2}=0.084, p<0.001\right)$. Additionally, TPC was significantly correlated with antioxidant activity as measured by both the CUPRAC $\left(\mathrm{r}^{2}=0.015, \mathrm{p}<0.001\right)$ and lipid peroxidation $\left(\mathrm{r}^{2}=0.015, \mathrm{p}<0.001\right)$ assays.

\subsection{Scavenging Activity Against DPPH Radical.}

The DPPH radical assay is most commonly used for investigating the antioxidant activities of natural compounds. In the DPPH assay, solvent fractions or extracts are tested for their ability to reduce the stable radical $\mathrm{DPPH}^{*}$ to the yellow-colored diphenylpicrylhydrazine. Specifically, the method is based on the reduction of alcoholic DPPH solution in the presence of a hydrogen-donating antioxidant, which results in the formation of a non-radical form of DPPH (DPPH-H) (Shon et al., 2003). As seen in Figure 2b, the ethyl acetate fraction of $S$. commune showed the highest activity in this assay $\left(70.52 \pm 2.17 \mathrm{mg} / \mathrm{mL} ; \mathrm{IC}_{50}-70 \mu \mathrm{g} / \mathrm{mL}\right)$, which was higher than 
the positive control (quercetin) at all concentrations tested $(0.1-1.0 \mathrm{mg} / \mathrm{mL})$. Among the different solvent fractions isolated from the crude extract, the dichloro methane, ethyl acetate, water residue, and hexane fractions, revealed no or only moderate activities in this assay. Thus, the ethyl acetate fraction showed the most potent activity, indicating that the compounds with the strongest DPPH radical scavenging activity in S. commune were of medium polarity. Notably, the observed activity of this fraction was significantly higher than all of the soluble fractions, the water residue, and the positive control, (quercetin at the same concentration).

\subsection{Reducing Power Assay (CUPRAC)}

The reducing power of antioxidant compounds can be indicated by their ability to reduce oxidized intermediates produced during the lipid peroxidation process by donating electrons. However, while the ferric-reducing antioxidant power (FRAP) assay is the most commonly used method for determining reducing potential of antioxidants, it has two major flaws: (1) FRAP assay is conducted under acidic condition (pH 3.6) to maintain iron solubility; (2) FRAP assay does not measure thiol antioxidants, such as glutathione. Thus, FRAP may not give values that are to physiological conditions. In the present study, we used the CUPRAC assay, which is based on the reduction of $\mathrm{Cu}$ (II) to $\mathrm{Cu}$ (I) by antioxidants. The reducing potentials for the different fractions of $S$. commune as determined by the CUPRAC assay, are presented in Figure 2c. The results indicated that the ethyl acetate fraction had the highest reducing power when compared with the positive control (quercetin). Notably, studies have indicated that the in vitro physiological procedure yields a higher reducing power than the chemical procedure (Perez-Jimenez J \& Saura-Calixto, 2005). In addition, there was a moderate correlation between reducing power of ethyl acetate fraction of $S$. commune and TPC $\left(\mathrm{r}^{2}=0.015, \mathrm{p}<0.001\right)$. Thus, ethyl acetate fraction exhibited the highest activity $(0.38 \pm 0.03)$, followed by the dichloromethane, crude, hexane, and water residue fractions.

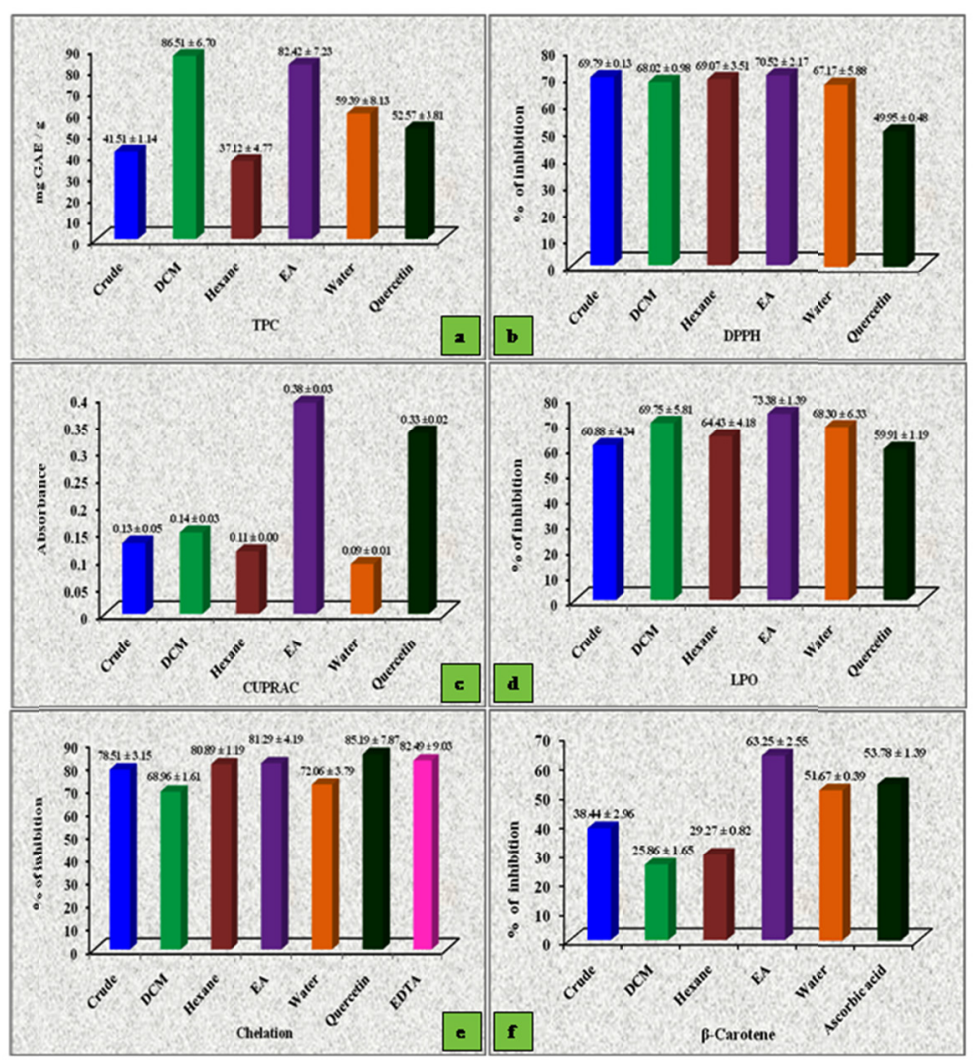

Figure 2. Total phenolic content (TPC) analysis (a) DPPH radical scavenging activity (b), antioxidant activity by CUPRAC (c), lipid peroxidation (LPO) activity (d), metal chelating ability (e), and $\beta$-carotene bleaching assay (f) are shown for the various solvent fractions from $S$. commune mushrooms at $1 \mathrm{mg} / \mathrm{mL}$

\subsection{Lipid Peroxidation Assay}

The unsaturated sites in fatty acids are easily attacked by free radicals, promoting the formation and regulation of 
lipid radicals. In this process, double bonds of lipids undergo rearrangements that result in destruction of lipids, producing breakdown products, such as malondialdehyde. Thus the estimation of malondialdehyde in a mushroom fraction helps to evaluate its protection level against lipid peroxidation, (i.e., antioxidants present in sample protect against the hazardous effects of free radicals on unsaturated fatty acids, minimizing the production of malondialdehyde) (Michielin et al., 2011). In our study, lipid peroxidation induced by $\mathrm{Fe}^{2+}$ was estimated by the presence of TBARS. The ability of the various $S$. commune solvent fractions to inhibit peroxidation of phospholipids in egg yolk is shown in Figure 2d. These data demonstrate that the, ethyl acetate fraction exhibited the highest inhibition of lipid peroxidation $\left(73.38 \pm 1.39 \% ; \mathrm{IC}_{50}-9.0 \mu \mathrm{g} / \mathrm{mL}\right)$ followed by dichloromethane $(69.75 \pm 5.81 \%)$ water residue $(68.30 \pm 6.33 \%)$ hexane $(64.43 \pm 4.18 \%)$ and crude extract $(60.88 \pm 4.34 \%)$ respectively. Moreover, quercetin showed a lower inhibition potential compared to the ethyl acetate fraction $(59.91 \pm 1.19 \%)$.

The process of lipid peroxidation has been suggested to proceed via a free radical chain reaction (Halliwell, 1989), which has been associated with cell membrane damage. This membranouse damage has been suggested to contribute to various diseases, including diabetes. Incubation of egg yolk homogenates in the presence of $\mathrm{FeSO}_{4}$ causes a significant increase in lipid peroxidation. It is possible that the high level of inhibition on lipid peroxidation displayed by the ethyl acetate fraction is related to the presence of phenolic compounds, which have been correlated with antioxidant activity (Gulcin et al., 2002).

\subsection{Metal Chelating Activity Assay}

Transition metals, such as iron, can stimulate lipid peroxidation by generating hydroxyl radicals through the Fenton reaction, accelerating lipid peroxidation into peroxyl and alkyl radicals. Therefore, these metals can drive the lipid peroxidation reaction. Chelating agents can inhibit radical generation by stabilizing transition metals, consequently reducing free radical damage. In addition, phenolic compounds have the potential to bind to metal ions due to their chemical structures, and have been shown to exhibit antioxidant activity through the chelation of metal ions (Zhao et al., 2008). For the metal chelating assay, chelating agents disturb, ferrozine complex formation resulting in a decrease in the red color. As shown in Figure 2e, the iron chelating ability of the ethyl acetate fraction $\left(81.29 \pm 4.19 \% ; \mathrm{IC}_{50}-49 \mu \mathrm{g} / \mathrm{mL}\right)$ was the most active, but was lower than that of ethyl acetate fraction and the controls, quercetin (85.19 $\pm 7.87 \%)$ and EDTA $(82.49 \pm 9.03 \%)$. Moreover, the chelating abilities of the other fractions, including hexane $(80.89 \pm 1.19 \%)$, crude $(78.51 \pm 3.15 \%)$, water residue $(72.06 \pm 3.79 \%)$ and dichloromethane $(68.96 \pm 1.61 \%)$. These data suggest, that the extracts can protect against oxidative damage by sequestering iron (II) ions, which may otherwise catalyze Fenton-type reactions or participate in metal catalyzed hydroperoxide decomposition reactions (Dorman et al., 2003). On the other hand, the iron (II) chelating properties of the fractions be attributed to the presence of endogenous chelating agents, mainly phenolics. In fact, certain phenolic compounds have functional groups that are oriented in a manner that, can allow chelation of metal ions (Thompson et al., 1976). Chelating agents may serve as secondary antioxidants because they reduce the redox potential, thereby stabilizing the oxidized form of metal ions. Thus we propose that the low moderate ferrous ion chelating effects of the ethyl acetate fraction could protect against oxidative damage.

\section{6 $\beta$ - carotene-linoleic Acid Bleaching Assay}

While iron (III) reduction and synthetic free radical scavenging models are valuable tools for analyzing the potential antioxidant activity of natural compounds, these systems do not use a food or biologically relevant oxidizable substrate; therefore, no direct information regarding protective action of the extracts can be determined (Dorman et al., 2003). For this reason, it was considered important to assess the inhibitory effect of $S$. commune extracts on the oxidation of $\beta$-carotene. In the $\beta$-carotene bleaching assay, oxidation of linoleic acid produces hydroperoxide-derived free radicals, which attack the chromophore of $\beta$-carotene. This, results in a bleaching of the reaction emulsion. Thus, an extract that is capable of retarding/inhibiting the oxidation of $\beta$-carotene can be described as a free radical scavenger and primary antioxidant (Liyana-Pathirana \& Shahidi, 2006).

As can be seen in Figure 2f, all of the extracts were capable of inhibiting the bleaching of $\beta$-carotene by scavenging linoleate-derived free radicals. The ethyl acetate fraction was more effective than (the ascorbic acid control) (63.25 $\pm 2.5 \%)$. It has been suggested that the polarity of an extract might impact its activity in water (i.e., non-polar compounds can be are more effective antioxidants than polar compounds due to a 'concentrating effect' within the lipid phase). However, in this work we have used different solvent fractions and found an appreciable inhibition of $\beta$-carotene bleaching using the ethyl acetate fraction of $S$. commune. This phenomenon has been described by Koleva and his co-author, who reported inhibition of bleaching of $\beta$-carotene by a polar extract of Sideritis species (Koleva et al., 2002). According to the $\beta$-carotene bleaching data, the ethyl fraction was capable 
of scavenging free radicals in a complex heterogeneous medium.

\subsection{Identification of Chemical Constituents in Ethyl Acetate Fraction by LC/MS Analysis}

The LC/MS chromatogram of the ethyl acetate fraction of $S$. commune at $240 \mathrm{~nm}$ is displayed in Figure 3. In addition, Table 1 shows the retention time, mode $(+/-), \lambda$ max, molecular weight, and the respective phytoconstituents identified. In the LC/MS analysis of the following were observed as negative molecular ions at $[\mathrm{MS}-\mathrm{H}]^{+}$: hydroxybenzoic acid at an $\mathrm{m} / \mathrm{z}$ of 138.12 , protocatechuic acid at at an $\mathrm{m} / \mathrm{z}$ of 154.12 , Vitamin $\mathrm{E}$ at an $\mathrm{m} / \mathrm{z}$ of 430.71 , and mevastatin at an $\mathrm{m} / \mathrm{z} 390.51$. Also, phenolic acids were observed as negative molecular ions at $[\mathrm{MS}-\mathrm{H}]^{+}$at $\mathrm{m} / \mathrm{z}$ of $293.0,297.0,323.0,327.0,367.0,379.0,383.0$ and 409.0. Notably, these compounds idendified in the ethyl acetate fraction of $S$. commune have been reported to have several biological activities. For example protocatechuic acid has antioxidant and anticancer activities (Tanaka \& Tanaka, 2011), vitamin E has been reported to possess antioxidant activity (Rezk et al., 1983), and mevastatin is an HMG-CoA reductase inhibitor (Hanjani et al., 2001).

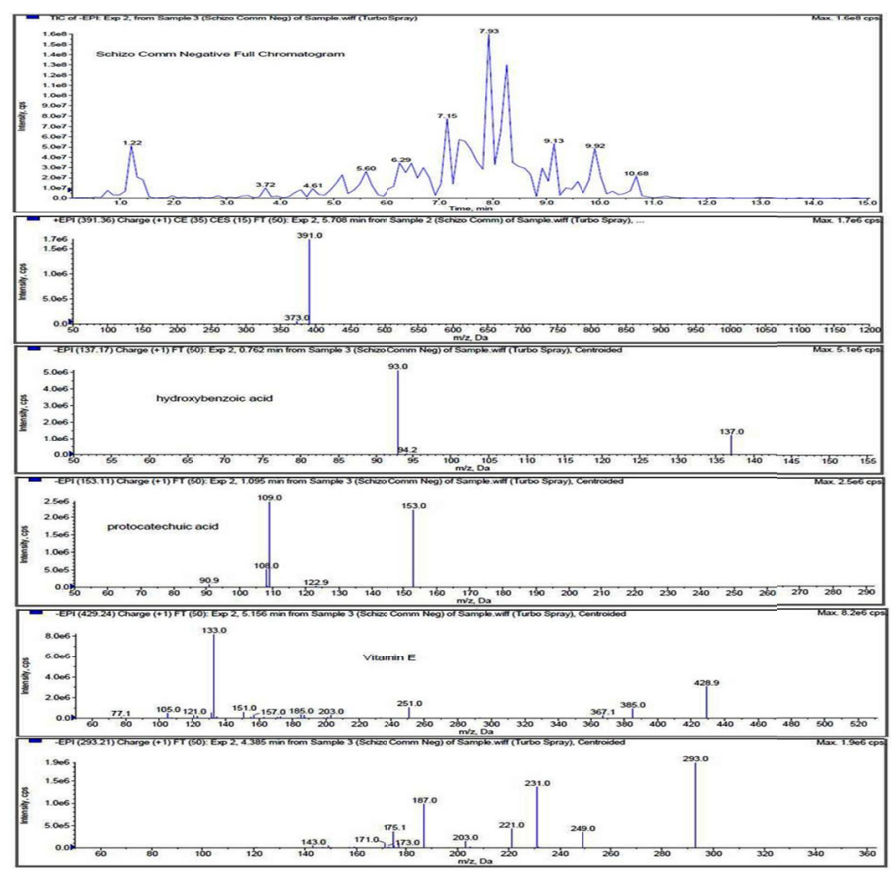

Figure 3. LCMS/MS chromatogram of the ethyl acetate fraction of S. commune mushroom

Table 1. Identification of non-volatile chemical constituents in ethyl acetate fraction of S. commune by LCMS/MS

\begin{tabular}{llllll}
\hline S. No & Rt (min) & Mode (+/-) & Compounds & Molecular formula & Molecular weight \\
\hline 1 & 0.762 & - & Hydroxybenzoic acid & $\mathrm{C}_{7} \mathrm{H}_{6} \mathrm{O}_{3}$ & 138.12 \\
2 & 1.095 & - & Protocatechuic acid & $\mathrm{C}_{7} \mathrm{H}_{6} \mathrm{O}_{4}$ & 154.12 \\
3 & 5.156 & - & Vitamin E & $\mathrm{C}_{29} \mathrm{H}_{50} \mathrm{O}_{2}$ & 430.71 \\
4 & 5.708 & - & Mevastatin & $\mathrm{C}_{23} \mathrm{H}_{34} \mathrm{O}_{5}$ & 390.50 \\
\hline
\end{tabular}

\subsection{Identification of Chemical Constituents in Ethyl Acetate Fraction by GC/MS Analysis}

The GC-MS chromatogram of the ethyl acetate fraction is displayed in Figure 4. As shown in Table 2, the 44 chemical constituents from GC/MS analysis were characterized based on peak area percentage and relative retention time (Rt), which were obtained from already published data (Tatsis et al., 2007). The major components present in the ethyl acetate fraction of S. commune were niacinamide (19.88\%), 4-pyridinecarboxamide (19.88\%), 9-octadecanamide (18.85\%), methyl-9-methyltetradecanoate (18.83\%), dodecanamide (17.26\%), hexadecanamide (17.26\%), linoleic acid ethyl ester $(17.10 \%)$, cycloeicosane $(16.23 \%)$, hexadecanoic acid, (methyl ester 14.85\%), 1-octadecane (14.23\%), and pentadecanoic acid, (methyl ester 13.83\%). Many of these compounds identified by GC/MS in the ethyl acetate fraction of S. commune have been suggested to have 
biological activities. In fact, niacinamide, was reported to be an effective dietary precursor for $\mathrm{NAD}^{+}$and to inhibit poly ADP-ribose polymerase-1 (PARP-1) activity (Surjana et al., 2010), In addition, ergosterol not only reduces inflammation related pain and decreases incidence of cardiovascular diseases, but also has antioxidant, antimicrobial, anticomplementary and antitumor activities (Yuan et al., 2006). Also, linoleic acid ethyl ester has been reported to possess antioxidant activity (Fagali \& Catala, 2008). Therefore, the presence of these phytochemicals makes S. commune a potential source of bioactive compounds.

Table 2 Identification of volatile chemical constituents in ethyl acetate fraction of S. commune by GC/MS

\begin{tabular}{|c|c|c|c|c|c|}
\hline S.No & Name of Compounds & $\begin{array}{l}\text { Retention } \\
\text { time }\end{array}$ & $\begin{array}{l}\text { Peak } \\
\text { Area (\%) }\end{array}$ & $\begin{array}{l}\text { Molecular } \\
\text { formula }\end{array}$ & $\begin{array}{l}\text { Molecular } \\
\text { weight }\end{array}$ \\
\hline 1 & Phenol & 3.705 & 3.57 & $\mathrm{C}_{6} \mathrm{H}_{5} \mathrm{OH}$ & 94.11 \\
\hline 2 & $\begin{array}{l}\text { Benzo }[1,2,5] \text { thiadiazole, } \\
\text { 4-bromo-7-(4-methylpiperazine) }\end{array}$ & 5.347 & 0.66 & $\mathrm{C}_{11} \mathrm{H}_{13} \mathrm{BrN}_{4} \mathrm{O}_{2} \mathrm{~S}_{2}$ & 377.28 \\
\hline 3 & 1,2- Benzenediol & 6.314 & 1.03 & $\mathrm{C}_{6} \mathrm{H}_{6} \mathrm{O}_{2}$ & 110.11 \\
\hline 4 & dl-Mevalonic acid lactone & 6.629 & 0.29 & $\mathrm{C}_{6} \mathrm{H}_{10} \mathrm{O}_{3}$ & 130.14 \\
\hline 5 & Indole & 7.664 & 0.43 & $\mathrm{C}_{8} \mathrm{H}_{7} \mathrm{~N}$ & 117.11 \\
\hline 6 & N-Acetylindole & 7.664 & 0.43 & $\mathrm{C}_{10} \mathrm{H}_{9} \mathrm{NO}$ & 159.06 \\
\hline 7 & 5H-1-Pyrindine & 7.664 & 0.43 & $\mathrm{C}_{8} \mathrm{H}_{9} \mathrm{~N}$ & 119.16 \\
\hline 8 & Benzaldehyde, 3-hydroxy & 8.506 & 0.37 & $\mathrm{C}_{7} \mathrm{H}_{6} \mathrm{O}_{2}$ & 122.12 \\
\hline 9 & L-Pipecolinic acid & 8.672 & 0.60 & $\mathrm{C}_{6} \mathrm{H}_{11} \mathrm{NO}_{2}$ & 129.20 \\
\hline 10 & Formyl glutamine & 8.672 & 0.60 & $\mathrm{C}_{6} \mathrm{H}_{10} \mathrm{~N}_{2} \mathrm{O}_{4}$ & 174.15 \\
\hline 11 & 4-Methylproline & 8.672 & 0.60 & $\mathrm{C}_{6} \mathrm{H}_{11} \mathrm{NO}_{2}$ & 129.15 \\
\hline 12 & Niacinamide & 9.152 & 19.88 & $\mathrm{C}_{6} \mathrm{H}_{6} \mathrm{~N}_{2} \mathrm{O}$ & 122.12 \\
\hline 13 & 4- Pyridinecarboxamide & 9.152 & 19.88 & $\mathrm{C}_{6} \mathrm{H}_{6} \mathrm{~N}_{2} \mathrm{O}$ & 122.14 \\
\hline 14 & Benzeneethanol, 4-hydroxy & 9.433 & 12.25 & $\mathrm{C}_{8} \mathrm{H}_{10} \mathrm{O}_{2}$ & 138.16 \\
\hline 15 & Phenol, 2,6-bis (1,1-dimethylethyl) & 10.360 & 0.45 & $\mathrm{C}_{14} \mathrm{H}_{22} \mathrm{O}$ & 206.32 \\
\hline 16 & Ethyl citrate & 12.099 & 0.64 & $\mathrm{C}_{12} \mathrm{H}_{20} \mathrm{O}_{7}$ & 276.28 \\
\hline 17 & n-Hexadecanoic acid & 15.206 & 1.83 & $\mathrm{C}_{16} \mathrm{H}_{32} \mathrm{O}_{2}$ & 256.42 \\
\hline 18 & Tridecanoic acid & 15.203 & 1.83 & $\mathrm{C}_{13} \mathrm{H}_{26} \mathrm{O}_{2}$ & 214.34 \\
\hline 19 & Chlorpyrifos & 15.629 & 0.17 & $\mathrm{C}_{9} \mathrm{H}_{11} \mathrm{Cl}_{3} \mathrm{NO}_{3} \mathrm{PS}$ & 350.59 \\
\hline 20 & 9,12-octadecadienoic acid & 16.499 & 0.40 & $\mathrm{C}_{18} \mathrm{H}_{32} \mathrm{O}_{2}$ & 280.44 \\
\hline 21 & Decanedioic acid, bis (2-ethylhexyl) ester & 22.210 & 2.00 & $\mathrm{C}_{26} \mathrm{H}_{50} \mathrm{O}_{4}$ & 426.67 \\
\hline 22 & Ergosterol & 25.591 & 14.12 & $\mathrm{C}_{28} \mathrm{H}_{44} \mathrm{O}$ & 396.65 \\
\hline 23 & Benzene, 1,2,3-trimethyl & 3.739 & 7.46 & $\mathrm{C}_{9} \mathrm{H}_{12}$ & 120.19 \\
\hline 24 & Benzene, 1,2-dimethyl & 4.471 & 1.56 & $\mathrm{C}_{8} \mathrm{H}_{10}$ & 106.17 \\
\hline 25 & Benzene, 2-ethyl-1,4-dimethyl & 4.826 & 1.17 & $\mathrm{C}_{10} \mathrm{H}_{14}$ & 134.21 \\
\hline 26 & Benzene, 1,2,4,5-tetramethyl & 5.290 & 1.49 & $\mathrm{C}_{10} \mathrm{H}_{14}$ & 134.22 \\
\hline 27 & 1,3,8-p-Menthatrine & 5.747 & 0.46 & $\mathrm{C}_{10} \mathrm{H}_{14}$ & 134.21 \\
\hline 28 & Azulene & 6.234 & 0.88 & $\mathrm{C}_{10} \mathrm{H}_{8}$ & 128.17 \\
\hline 29 & Naphthalene & 6.234 & 0.88 & $\mathrm{C}_{10} \mathrm{H}_{8}$ & 128.17 \\
\hline 30 & Undecane & 7.601 & 1.33 & $\mathrm{C}_{11} \mathrm{H}_{24}$ & 156.31 \\
\hline 31 & Octane, 2-methyl & 7.601 & 1.33 & $\mathrm{C}_{9} \mathrm{H}_{20}$ & 128.25 \\
\hline 32 & Tridecane & 7.601 & 1.33 & $\mathrm{C}_{13} \mathrm{H}_{28}$ & 184.36 \\
\hline 33 & Niacinamide & 8.923 & 3.91 & $\mathrm{C}_{6} \mathrm{H}_{6} \mathrm{~N}_{2} \mathrm{O}$ & 122.12 \\
\hline 34 & Phenol, 2-ethyl & 9.324 & 1.09 & $\mathrm{C}_{8} \mathrm{H}_{10} \mathrm{O}$ & 122.16 \\
\hline 35 & Pentadecanoic acid, methyl ester & 13.833 & 1.08 & $\mathrm{C}_{16} \mathrm{H}_{32} \mathrm{O}_{2}$ & 256.42 \\
\hline 36 & Methyl 9-methyltetradecanoate & 18.833 & 1.08 & $\mathrm{C}_{16} \mathrm{H}_{32} \mathrm{O}_{2}$ & 256.42 \\
\hline 37 & 1-Octadecane & 14.239 & 0.49 & $\mathrm{C}_{18} \mathrm{H}_{36}$ & 252.48 \\
\hline 38 & Hexadecanoic acid, methyl ester & 14.857 & 3.29 & $\mathrm{C}_{17} \mathrm{H}_{34} \mathrm{O}_{2}$ & 270.45 \\
\hline 39 & Cycloeicosane & 16.236 & 0.40 & $\mathrm{C}_{20} \mathrm{H}_{40}$ & 280.53 \\
\hline 40 & Linoleic acid ethyl ester & 17.106 & 2.91 & $\mathrm{C}_{20} \mathrm{H}_{36} \mathrm{O}_{2}$ & 308.49 \\
\hline 41 & Dodecanamide & 17.266 & 5.31 & $\mathrm{C}_{12} \mathrm{H}_{25} \mathrm{NO}$ & 199.33 \\
\hline 42 & Hexadecanamide & 17.266 & 5.31 & $\mathrm{C}_{16} \mathrm{H}_{33} \mathrm{NO}$ & 255.44 \\
\hline 43 & 9-Octadecanamide & 18.857 & 23.70 & $\mathrm{C}_{18} \mathrm{H}_{35} \mathrm{NO}$ & 281.47 \\
\hline 44 & Benzene, 1,2,3-trimethyl & 3.739 & 7.46 & $\mathrm{C}_{9} \mathrm{H}_{12}$ & 120.19 \\
\hline
\end{tabular}




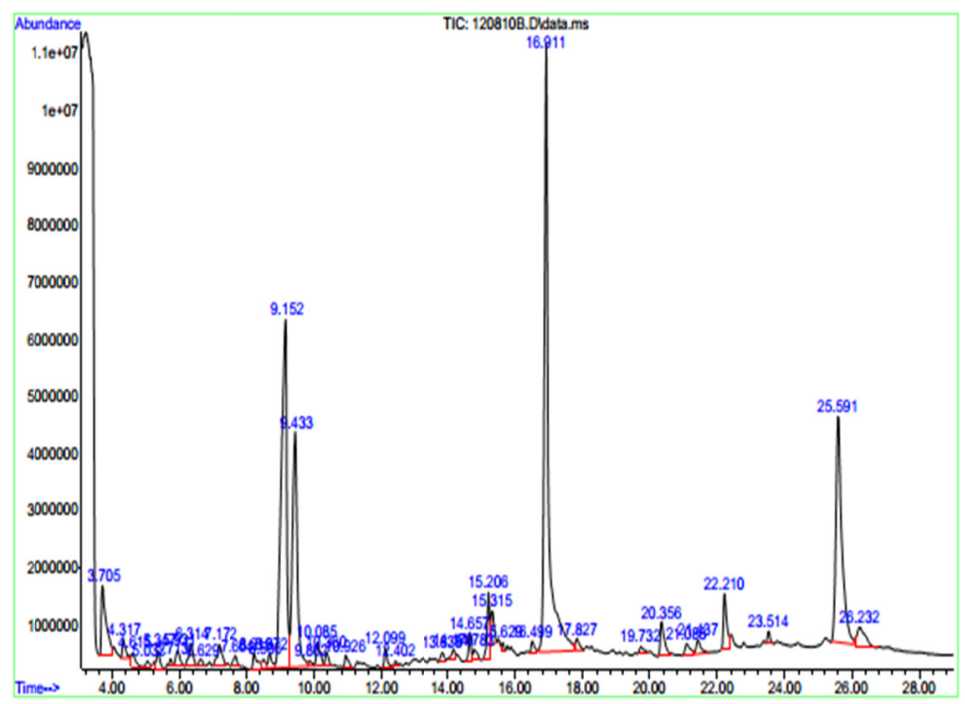

Figure 4. GC/MS chromatogram of the ethyl acetate fraction of S. commune mushroom

Here, we have demonstrated that the ethyl acetate fraction of S. commune has antioxidant compounds that can protect against oxidative damage in our bodies and prevent chronic diseases. The impact of these compounds on human health and in the control of free radical mediated diseases will need to be determined through future in vivo studies. These natural constituents could be exploited as cost effective food/feed additives for human and animal health.

\section{Acknowledgements}

The authors gratefully thank the Mushroom Research Centre at the University of Malaya for the facilities and the Ministry of Higher Education for the High Impact Research grant HIR-MOHE F000002-21001.

\section{References}

Anderson, D. (1999). Antioxidant defences against reactive oxygen species causing genetic and other damage. Mutation Research, 350, 103-108. http://dx.doi.org/10.1016/0027-5107(95)00096-8

Cao, G., Sofic, E., \& Prior, R. L. (1997). Antioxidant and prooxidant behaviour of flavonoids: Structure-activity

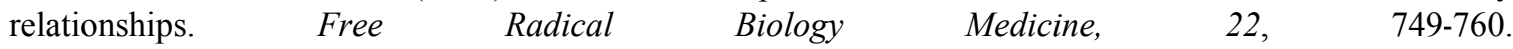
http://dx.doi.org/10.1016/S0891-5849(96)00351-6

Cheung, L. M., Cheung, P. C. K., \& Ooi, V. E. C. (2005). Mushroom extracts with antioxidant activity against lipid peroxidation. Food Chemistry, 89, 403-409. http://dx.doi.org/10.1016/j.foodchem.2004.02.049

Daker, M., Abdullah, N., Vikineswary, S., Goh, P. C., \& Kuppusamy, U. R. (2008). Antioxidant from maize and maize fermented By Marasmiellus sp. as stabiliser of lipid-rich foods. Food Chemistry, 107, 1092-1098.

Dastmalchi, K. D., Doeman, H. J. D., Oinonen, P. P., Darwis, Y., Laaso, I., \& Hiltunen, R. (2008). Chemical composition and in vitro antioxidative activity of a lemon balm (Melissa officinalis L.) extract. LWT- Food Science and Technology, 41, 391-400. http://dx.doi.org/10.1016/j.lwt.2007.03.007

Dorman, H. J. D., Peltoketo, A., Hiltunen, R., \& Tikkanen, M. J. (2003). Characterization of the antioxidant property of de-odourzede extract from selected Laminaceae herbs. Food Chemistry, 83, 255-262. http://dx.doi.org/10.1016/S0308-8146(03)00088-8

Duan, X. J., Zhang, W. W., Li, X. M., \& Wang, B. G. (2006). Evaluation of antioxidant property of extract and fractions obtained from a red alga, Polysiphonia urceolata. Food Chemistry, 95, 37-43. $\mathrm{http}: / / \mathrm{dx}$.doi.org/10.1016/j.foodchem.2004.12.015

Fagali, N., \& Catala, A. (2008). Antioxidant activity of conjugated linoleic acid isomers, linoleic acid and its methyl ester determined by photoemission and DPPH Techniques. Biophysical Chemistry, 137, 56-62. http://dx.doi.org/10.1016/j.bpc.2008.07.001

Ferreira, I. C. F. R., Baptista, P., Vilas-Boas, M., \& Barros, L. (2006). Free radical scavenging capacity and reducing power of wild edible mushrooms from northeast Portugal: individual cap and stipe activity. Food Chemistry, 100, 1511-1516. http://dx.doi.org/10.1016/j.foodchem.2005.11.043 
Gulcin, I., Buyukokuroglu, M. E., Oktay, M., \& Kufrevioglu, O. I. (2002). On the in vitro antioxidant properties of melatonin. Journal of Pineal Research, 33, 167-171. http://dx.doi.org/10.1034/j.1600-079X.2002.20920.x

Halliwell, B. (1989). Protection against tissue damage in vivo by desferrioxamine: What is its mechanism of action. Free Radical Biology Medicine, 7, 645-651. http://dx.doi.org/10.1016/0891-5849(89)90145-7

Halliwell, B. (1996). Antioxidants in human health and disease. Annual Review of Nutrition, 16, 33-49. http://dx.doi.org/10.1146/annurev.nu.16.070196.000341

Hanjani, S. A., Stagliano, N. E., Yamada, M., Huang, P. L., Liao, J. K., \& Moskowitz, M. A. (2001). Mevastatin, an HMG-CoA reductase inhibitor, reduces stroke damage and upregulates endothelial nitric oxide synthase in mice. Stroke, 32, 980-986. http://dx.doi.org/10.1161/01.STR.32.4.980

Koleva, I. I., Van beek, T. A., Linseen, J. P. H., Linseen de Groot, A., \& Evstatieva, L. N. (2002). Screening of plant extracts for antioxidant activity: A comparative study on three testing methods. Phytochemical Analysis, 13. http://dx.doi.org/8-17. 10.1002/pca.611

Lindequist, U., Niedermeyer, T. H. J., \& Julich, W. D. (2008).The pharmacological potential of mushrooms. Evidence Based Complementary and Alternative Medicine (eCAM), 2, 285-299.

Liyana-Pathirana, C. M., \& Shahidi, F. (2006). Antioxidant properties of commercial soft and hard winter wheats (Triticum aestivum L) and their milling fractions. Journal of Food Agriculture, 86, 477-485. http://dx.doi.org/10.1002/jsfa.2374

Michielin, E. M. Z., Wiese, L. P. L., Ferreira, E. A., Pedrosa, R. C., \& Ferreira, S. R. S. (2011). Radical-scavenging activity of extracts from Cordia verbenacea DC obtained by different methods. The Journal of Supercritical Fluids, 86, 89-96. http://dx.doi.org/10.1016/j.supflu.2010.11.006

Noorlidah, A., Marjiana, I. S. M., Norhaniza, A., Adawiyah, S. S., \& Beng, F. L. (2012). Evaluation of selected culinary-medicinal mushrooms for antioxidant and ACE inhibitory activities. Evidence Based Complementary and Alternative Medicine (eCAM), 2012, 1-12. http://dx.doi.org/ 10.1155/2012/464238

Oso, B. A. (1981). Fungi and Mankind. Inaugural Lecture. University of Ibadan (Nigeria).

Ozturk, M., Aydogmus, F., Duru, M. E., \& Topcu, G. (2007). Antioxidant activity of stem and root extracts of Rhubarb (Rheumribes): an edible medicinal plant. Food Chemistry, 103, 623-630. http://dx.doi.org/10.1016/j.foodchem.2006.09.005

Perez-Jimenez, J., \& Saura-Calixto, F. (2005). Literature data may underestimate the actual antioxidant capacity of cereals. Journal of Agricultural Food Chemistry, 53, 5036-5040. http://dx.doi.org/10.1021/jf050049u

Rabajoli, F., Arneodo, D., Balzola, F., Leo, L., \& Vineis, P. (1996). Moderate alcohol intake and risk of myocardial infarction among non-smokers. European Journal of Publlic Health, 6, 227-30. http://dx.doi.org/10.1093/eurpub/6.3.227

Rezk, B. M., Haenen, G. R. M. M., Van der Vijgh, W. J. F., \& Bast, A. (2004). The extraordinary antioxidant activity of vitamin E phosphate. Biochimica et Biophysica Acta, 1983, 16-21. http://dx.doi.org/10.1016/j.bbalip.2004.03.005

Shon, M. Y., Kim, T. H., \& Sung, N. J. (2003). Antioxidants and free radical scavenging activity of Phellinus baumii (Phellinus of Hymenochaetaceae) extracts. Food Chemistry, 82, 593-597. http://dx.doi.org/10.1016/S0308-8146(03)00015-3

Slinkard, K., \& Singleton, V. L. (1977). Total phenol analyses: automation and comparison with manual methods. American Journal of Enology and Viticulture, 28, 49-55.

Surjana, D., Halliday, G. M., \& Damian, D. L. (2010). Role of Nicotinamide in DNA Damage, Mutagenesis, and DNA Repair. Journal of Nucliec Acids, 1-13. http://dx.doi.org/10.4061/2010/157591

Tanaka, T., \& Tanaka, M. (2011). Potential cancer chemopreventive activity of protocatechuic acid. Journal of Experimental Clinical Medicine, 3, 27-33. http://dx.doi.org/10.1016/j.jecm.2010.12.005

Tatsis, E. C., Boeren, S., Exarchou, V., Troganis, A. N., Vervoort, J., \& Gerothanassis, I. P. (2007). Identification of the major constituents of Hypericum perforatum by LC/SPE/NMR and/or LC/MS. Phytochemistry, 68, 383-393. http://dx.doi.org/10.1016/j.phytochem.2006.11.026

Thompson, M., Williams, C.R., \& Elliot, G. E. (1976). Stability of flavonoid complexes of copper (II) and flavonoid antioxidant activity. Analytica Chimica Acta, 85, 375-381. http://dx.doi.org/10.1016/S0003-2670(01)84703-6 
Wasser, S. P., \& Weis, A. L. (1999).Therapeutic effects of substances occurring in higher basidiomycetes mushrooms: a modern perspective. Critical Review Immunology, 19, 65-96.

Yim, H. S., Chye, F. Y., Ho, S. K., \& Ho, C. W. (2009). Phenolic profiles of selected edible wild mushrooms as affected by extraction solvent, time and temperature. Asian Journal of Food Agro-Industry, 2, 392-401.

Yuan, J. P., Wang, J. H., Liu, X., Kuang, H. C., \& Huang, X. N. (2006). Determination of ergosterol in ganoderma spore lipid from the germinating spores of Ganoderma lucidum by high-performance liquid chromatography. Journal of Agriculture Food Chemistry, 54, 6172-6176. http://dx.doi.org/ 10.1021/jf0617059

Zhao, H., Fan, W., Dong, J., Lu, J., Chen, J., Shan, L., Lin, Y., \& Kong, W. (2008). Evaluation of antioxidant activities and total phenolic contents of typical malting barley varieties. Food Chemistry, 107, 296-304. http://dx.doi.org/10.1016/j.foodchem.2007.08.018 